\title{
Characterisation of a solvent-tolerant haloarchaeal $(R)$-selective transaminase isolated from a Triassic period salt mine
}

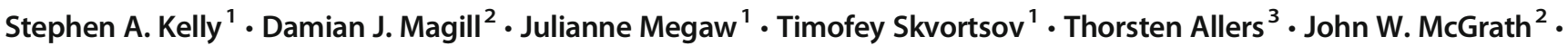 \\ Christopher C. R. Allen ${ }^{2}$. Thomas S. Moody ${ }^{4,5}$ Brendan F. Gilmore ${ }^{1}$
}

Received: 13 March 2019 / Revised: 26 March 2019 / Accepted: 29 March 2019 / Published online: 23 May 2019

(C) The Author(s) 2019

\begin{abstract}
Transaminase enzymes (TAms) are becoming increasingly valuable in the chemist's toolbox as a biocatalytic route to chiral amines. Despite high profile successes, the lack of $(R)$-selective TAms and robustness under harsh industrial conditions continue to prove problematic. Herein, we report the isolation of the first haloarchaeal TAm (BC61-TAm) to be characterised for the purposes of pharmaceutical biocatalysis. BC61-TAm is an $(R)$-selective enzyme, cloned from an extremely halophilic archaeon, isolated from a Triassic period salt mine. Produced using a Haloferax volcanii-based expression model, the resulting protein displays a classic halophilic activity profile, as well as thermotolerance (optimum $50{ }^{\circ} \mathrm{C}$ ) and organic solvent tolerance. Molecular modelling predicts the putative active site residues of haloarchaeal TAms, with molecular dynamics simulations providing insights on the basis of BC61-TAm's organic solvent tolerance. These results represent an exciting advance in the study of transaminases from extremophiles, providing a possible scaffold for future discovery of biocatalytic enzymes with robust properties.
\end{abstract}

Keywords Archaea $\cdot$ Biocatalysis $\cdot$ Halophile $\cdot$ Organic solvent $\cdot$ Transaminase

\section{Introduction}

Chiral amines are valuable building blocks for the pharmaceutical industry, representing versatile intermediates in the synthesis of active pharmaceutical ingredients (APIs). Their synthesis using conventional chemical means can suffer from a number of critical drawbacks, including the need for volatile

Electronic supplementary material The online version of this article (https://doi.org/10.1007/s00253-019-09806-y) contains supplementary material, which is available to authorized users.

Brendan F. Gilmore

b.gilmore@qub.ac.uk

School of Pharmacy, Queen's University Belfast, Belfast, UK

2 School of Biological Sciences, Queen's University Belfast, Belfast, UK

3 School of Life Sciences, University of Nottingham, Queen's Medical Centre, Nottingham, UK

4 Almac, Department of Biocatalysis \& Isotope Chemistry, 20 Seagoe Industrial Estate, Craigavon, UK

5 Arran Chemical Company Limited, Unit 1 Monksland Industrial Estate, Athlone, Co. Roscommon, Ireland organic solvents and toxic transition metal catalysts, as well as a lack of enantioselectivity in a single step (Malik et al. 2012).

Biocatalytic routes to optically active amines have emerged as a 'green' alternative to conventional synthetic chemistry approaches, expanding the chemist's toolbox and affording an economically viable approach for the production of these valuable compounds. The ability of biocatalysts to operate in aqueous media, as well as at ambient temperature and neutral $\mathrm{pH}$, makes them extremely desirable and useful in streamlining API synthesis.

To date, a number of enzymes have been employed in the production of chiral amines, including hydrolases, lyases, oxidases and dehydrogenases (Busto et al. 2011; Kroutil et al. 2013; Sharma et al. 2017). The demand for efficient production of optically active amines has also driven research into the use of transaminase enzymes (TAms) for this purpose.

TAms are pyridoxal phosphate (PLP)-dependent enzymes capable of transferring an amine group from a donor molecule to a prochiral ketone, resulting in the formation of a chiral amine. Their use in industrial biocatalysis has been the subject of a number of recent reviews (Malik et al. 2012; Ghislieri and Turner 2013; Kohls et al. 2014; Guo and Berglund 2017; Kelly et al. 2018). TAms have been employed in the synthesis 
of a number of drug molecules (Fuchs et al. 2010; Mangion et al. 2012; Midelfort et al. 2013), with their capabilities best showcased in the production of the antidiabetic drug sitagliptin (Savile et al. 2010). In this highly successful example, a bacterial TAm, optimised by protein engineering, brought about the conversion of the prochiral ketone prositagliptin to the chiral amine molecule sitagliptin. As well as replacing a number of chemical steps, including a hydrogenation step requiring expensive high-pressure equipment, this biocatalytic approach also improved overall yield and reduced waste.

TAms, as with other enzymes, are not without drawbacks. A narrow substrate scope and an inability to deal with challenging conditions often demanded by industrial processes, highlight the need for improvement of the current TAm toolbox. Whilst TAms possess the advantage of being highly enantioselective, a consideration which is critical for pharmaceutical production, the lack of $(R)$-selective TAms in the current catalogue is an issue which must be addressed. Important steps have been taken in order to overcome this barrier, including the use of rational design to reverse the enantiopreference of TAms (Svedendahl et al. 2010; Humble et al. 2012), but the issue remains problematic. The discovery of naturally $(R)$-selective TAms, whilst challenging, is the most obvious route to address this current impasse.

Shortfalls encountered with currently available TAms have led to a number of approaches for improvement and processspecific optimisation. Protein engineering has brought about significant advances in both activity and substrate range (Savile et al. 2010; Nobili et al. 2015; Dourado et al. 2016), whilst another viable option is the search for novel enzymes with naturally optimised capabilities, such as enzymes from environments whose conditions more closely mimic those of industrial processes. With the majority of current enzymes derived from culturable mesophilic bacteria, the quest for new TAms has been expanded to include metagenomic mining, including those from the archaeal domain, and from extreme environments (Littlechild 2015; Baud et al. 2017; Bezsudnova et al. 2017).

Interrogation of extreme environments has focused heavily on enzymes from thermophilic organisms, which have been studied in much greater detail relative to their halophilic counterparts. Scarcely is this trend more evident than with halophilic TAms, where the number of enzymes has been quite limited to date (Muriana et al. 1991). This is surprising given the range of extreme conditions halophilic microorganisms, and often by extension their enzymes, can tolerate not only functioning at high salt concentrations but also with increased temperatures, in organic solvent, and often at elevated $\mathrm{pH}$ (Hough and Danson 1999; Doukyu and Ogino 2010; Amoozegar et al. 2017). This 'polyextremophilicity' indicates that halophilic enzymes have the ability to tolerate a range of harsh conditions, and with it the ability to effectively 'green' a multitude of industrial processes.

The most extreme adaptations of halophiles are generally the reserve of haloarchaea. Archaea represents the third domain of life, proposed for the first time as recently as 1990 (Woese et al. 1990). As such, they remain hugely understudied relative to their bacterial counterparts, and represent a potentially vast untapped resource of novel and diverse biocatalysts.

In this study, we describe a TAm from a haloarchaeon, Halorubrum sp. CSM-61, isolated from a Triassic period halite deposit (formed circa 220-250 mya). To our knowledge, this is the first example of a haloarchaeal TAm to be cloned and overexpressed and investigated for its potential use in biocatalysis.

\section{Materials and methods}

\section{Organism isolation and identification}

Organism CSM-61 was isolated by inoculating media containing (per litre) rock salt from Kilroot salt mine $(250 \mathrm{~g})$, yeast extract $(10 \mathrm{~g})$, casein hydrolysate $(7.5 \mathrm{~g})$ and glycerol $(10 \mathrm{~mL})$ with $100 \mu \mathrm{L}$ undiluted brine collected from a brine stream within the mine. Identification was based on the $16 \mathrm{~S}$ rRNA gene and performed using colony PCR as described previously (Supporting information; Kelly et al. 2017), using the universal primers ARCH $21 \mathrm{~F}\left(5^{\prime}-\mathrm{TTCC}\right.$ GGTTGATCCYGCCGGA-3') and 958R (5'-YCCGGCGT TGAMTCCAATT-3').

\section{DNA extraction and PCR amplification of BC61-TAm gene}

Genomic DNA was extracted and sequenced, and the assembled genome annotated and BC61-TAm identified as described previously (Supporting information; Kelly et al. $2017)$. For ward ( $5^{\prime}$ - T T T T T T C CAT GG GAT T CGACGAGATGGAC- $3^{\prime}$ ) and reverse (5'-TTTTTTGAAT TCTTATACGTAGGTGAACCAGTCGTC-3') primers were designed specific to the gene sequence (Invitrogen, UK) with restriction sites included for $\mathrm{N} c o \mathrm{I}$ and $E c o$ RI-HF respectively (highlighted in bold). The BC61-TAm gene was amplified and checked as described previously (Supporting information; Kelly et al. 2017).

\section{Preparation of pTA1228/BC61-TAm plasmid and transformation of Escherichia coli}

The pTA1228/BC61-TAm plasmid was prepared as follows: $25 \mu \mathrm{L}$ pTA 1228 vector was cut using restriction enzymes $P$ ciI $(1 \mu \mathrm{L})$ in Tango buffer $(3 \mu \mathrm{L})$ (Thermo Fisher Scientific, UK) 
and EcoRI-HF ( $1 \mu \mathrm{L})$ in CutSmart buffer $(3 \mu \mathrm{L})$ in two separate single digests, with purification between each digest using a GeneJet PCR Purification kit (Thermo Fisher Scientific, UK). Alkaline Calf Intestinal Phosphatase (CIP) (NEB) was subsequently added to the pTA1228 mix and incubated for a further $1 \mathrm{~h}$ at $37^{\circ} \mathrm{C}$. BC61-TAm gene was cut using NcoI $(1 \mu \mathrm{L})$ and EcoRI-HF $(1 \mu \mathrm{L})$ in CutSmart buffer $(3 \mu \mathrm{L})$ in a double digest, followed by PCR purification. Ligation and transformation of One Shot ${ }^{\circledR}$ TOP 10 Chemically Competent $E$. coli cells were carried out as described previously (Supporting information; Kelly et al. 2017).

\section{Transformation of $H f x$. volcanii H1424 with pTA1228/BC61-TAm}

Hfx. volcanii H1424 cells (Stroud et al. 2012) were transformed using a protocol described previously by the Allers group (Nuttall et al. 2009). A primary culture of $H f x$. volcanii $\mathrm{H} 1424\left(10 \mathrm{~mL}, \mathrm{OD}_{550} \approx 0.8\right)$ was pelleted at $6000 \mathrm{rpm}$ for $8 \mathrm{~min}$. The pellet was suspended in $2 \mathrm{~mL} 50 \mathrm{mM}$ Tris- $\mathrm{HCl}$, pH 8.5 buffer containing $\mathrm{NaCl}(1 \mathrm{M}), \mathrm{KCl}(27 \mathrm{mM})$ and $15 \%$ sucrose, before pelleting again with the same conditions. The pellet was gently resuspended in $600 \mu \mathrm{L}$ unbuffered spheroplasting solution containing $\mathrm{NaCl}(1 \mathrm{M}), \mathrm{KCl}$ (27 $\mathrm{mM}$ ) and $15 \%$ sucrose, and $200 \mu \mathrm{L}$ transferred to a clean, 2-mL round-bottomed tube for each transformation. $0.5 \mathrm{M}$ EDTA, pH $8.0(20 \mu \mathrm{L})$, was added to the side of the tube, inverted to mix and left for $10 \mathrm{~min}$ at room temperature. DNA samples were prepared with $10 \mu \mathrm{L}$ pTA228/BC61-TAm plasmid $(\sim 1 \mu \mathrm{g})$, unbuffered spheroplasting solution $(15 \mu \mathrm{L})$ and $0.5 \mathrm{M}$ EDTA, pH $8.0(5 \mu \mathrm{L})$. This mixture was added to the cell suspension as described before and left for $5 \mathrm{~min}$ at room temperature. An equal volume of $60 \% \mathrm{PEG}_{600}$ in unbuffered spheroplasting solution was added in the same manner as before, the tube shaken horizontally to mix and left for $30 \mathrm{~min}$ at room temperature. The mixture was diluted with $1.5 \mathrm{~mL}$ spheroplast dilution solution (Nuttall et al. 2009), inverted to mix and left for $2 \mathrm{~min}$ at room temperature, before pelleting at $6000 \mathrm{rpm}$ for $8 \mathrm{~min}$. The supernatant was discarded and $1 \mathrm{~mL}$ regeneration solution (Nuttall et al. 2009) was added, with a wide-bore pipette used to transfer the pellet and solution to a 5-mL sterile tube. This was incubated undisturbed at $45^{\circ} \mathrm{C}$ for $2 \mathrm{~h}$, before leaving for a further $4 \mathrm{~h}$ with rotation. Following incubation, cells were transferred to a $2-\mathrm{mL}$ roundbottomed tube and centrifuged at $6000 \mathrm{rpm}$ for $8 \mathrm{~min}$, with the resultant pellet resuspended in $1 \mathrm{~mL}$ transformant dilution solution (Nuttall et al. 2009). Suspensions were diluted further to $10^{-1}$ and $10^{-2}$ with transformant dilution solution and plated on Hv-Ca+ agar (Nuttall et al. 2009) and incubated at $45{ }^{\circ} \mathrm{C}$. After around 1 week, colonies were restreaked on $\mathrm{Hv}-\mathrm{Ca}+$ agar for purity, with fresh colonies used to inoculate $5 \mathrm{~mL} \mathrm{Hv}-\mathrm{Ca}+$ broth and incubated at $45^{\circ} \mathrm{C}$ with rotation.
Protein expression was carried out based on an adapted method described previously (Liliensiek et al. 2013). When primary cultures reached $\mathrm{OD}_{550} \approx 1.0$, they were used to inoculate $1 \mathrm{~L} \mathrm{Hv}$-YPC broth (Allers et al. 2004) containing $5 \mathrm{mM} \mathrm{L-}$ tryptophan and incubated at $45^{\circ} \mathrm{C}$ with rotation to an $\mathrm{OD}_{550} \approx$ 1.0. Following incubation, the culture was pelleted via centrifugation, freeze-thawed at $-80^{\circ} \mathrm{C}$, suspended in $50 \mathrm{mM}$ Tris$\mathrm{HCl}$ buffer, $\mathrm{pH} 7.5$ containing $2 \mathrm{M} \mathrm{NaCl}$ and $2 \mathrm{mM}$ EDTA, and sonicated on ice. This was further centrifuged to remove cell debris. The supernatant was clarified using $0.8 \mu \mathrm{M}$ filters and purified as described below.

\section{His-tag-mediated purification and expression analysis of BC61-TAm protein}

BC61-TAm protein was purified from clarified cell-free extract (CFE) by immobilised metal affinity chromatography (IMAC) using the N-terminal $6 \times$ His-tag encoded by the pTA 1228 vector. An ÄKTA Prime Plus Liquid Chromatography System was used to load the CFE on a HisTrap $^{\text {TM }}$ HP $1 \mathrm{~mL}$ column (both GE Healthcare Life Sciences, UK) at a rate of $1 \mathrm{~mL} \mathrm{~min}^{-1}$. This was washed using buffer containing $20 \mathrm{mM}$ HEPES, pH 7.5, $2 \mathrm{M} \mathrm{NaCl}, 20 \mathrm{mM}$ imidazole, $1 \mathrm{mM}$ PMSF made up to $1 \mathrm{~L}$ with $\mathrm{dH}_{2} \mathrm{O}$. Purified protein was eluted in $1 \mathrm{~mL}$ fractions using buffer containing $20 \mathrm{mM}$ HEPES, pH 7.5, $2 \mathrm{M} \mathrm{NaCl}, 500 \mathrm{mM}$ imidazole, $1 \mathrm{mM}$ PMSF adjusted to $1 \mathrm{~L}$ with $\mathrm{dH}_{2} \mathrm{O}$. Recombinant BC61-TAm protein was analysed via SDS-PAGE.

\section{HPLC-based screening assay employing $(R)$ -methylbenzylamine as amino donor}

(R)-Methylbenzylamine (MBA) $(25 \mathrm{mM})$ and PLP $(0.5 \mathrm{mM}$ in potassium phosphate buffer, $100 \mathrm{mM}$, $\mathrm{pH}$ 8.0, $2 \mathrm{M} \mathrm{KCl})$, and $\alpha$-ketoglutarate $(\alpha-\mathrm{KG})(5 \mathrm{mM})$ were added to a 96-well deep well plate to give a total volume of $180 \mu \mathrm{L}$. The reaction was initiated by the addition of $20 \mu \mathrm{L}$ purified BC61-TAm to a final working concentration of $1 \mathrm{mg} / \mathrm{mL}$. After incubation for $16 \mathrm{~h}$ at $45{ }^{\circ} \mathrm{C}$ and $1200 \mathrm{rpm}$, the reaction was quenched with $800 \mu \mathrm{L} 62.5 \%$ acetonitrile and denatured protein was removed by centrifugation. Two hundred microlitres of supernatant was removed for analysis by HPLC using an XSelect ${ }^{\circledR} \mathrm{CSH}^{\mathrm{TM}} \mathrm{C} 185 \mu \mathrm{M}$ column $(4.6 \times 250 \mathrm{~mm})$ and an Agilent 1260 Infinity model. Detection of acetophenone coproduct was carried out at $240 \mathrm{~nm}$, in an adaptation of a previously described study (Schätzle et al. 2009). The concentration of acetophenone coproduct formation was determined over 11 min using a gradient of 5-95\% organic solvent (where $\mathrm{A}=\mathrm{dH}_{2} \mathrm{O}$ with $0.1 \%$ $\mathrm{H}_{3} \mathrm{PO}_{4}$ and $\mathrm{B}=$ acetonitrile with $0.1 \% \mathrm{H}_{3} \mathrm{PO}_{4}$ ). Acetophenone eluted at a retention time of $8.6 \mathrm{~min}$. Assays using both BC61-TAm and elution buffer negative 
controls were carried out in triplicate for each substrate, with an average conversion taken for each and values for negative control subtracted from BC61-TAm values.

To assess the effect of temperature on enzyme performance, assays were set up as described above but incubated at different temperatures, ranging from 30 to $60^{\circ} \mathrm{C}$.

To assess the effect of changing $\mathrm{pH}$ on enzyme performance, assays were set up using a universal buffer (Davies 1959), containing $25 \mathrm{mM}$ citric acid, $25 \mathrm{mM} \mathrm{KH}_{2} \mathrm{PO}_{4}, 25 \mathrm{mM}$ Tris, $12.5 \mathrm{mM} \mathrm{Na}_{2} \mathrm{~B}_{4} \mathrm{O}_{7}$ and $2 \mathrm{M} \mathrm{KCl}$, adjusted using $\mathrm{NaOH}$, with $\mathrm{pH}$ values from $\mathrm{pH} 6.0$ to 11.0 investigated.

To assess the effect of organic solvents on enzyme performance, more concentrated stock solutions of potassium phosphate buffer ( $\mathrm{pH}$ 8.0) were prepared to reduce the aqueous volume in the reaction, with PLP concentrations also adjusted in buffer solutions accordingly. Once diluted by the required amount of organic solvent, the overall concentrations of potassium phosphate buffer ( $\mathrm{pH} 8.0$ ), PLP and $\mathrm{KC} 1$ in solution remained at $100 \mathrm{mM}, 0.5 \mathrm{mM}$ and $2 \mathrm{M}$ as before. Concentrations of organic solvents investigated ranged from 0 to $30 \%$.

Kinetic parameters were determined using the reaction described above, with $\alpha-K G$ concentration varied from 1 to $20 \mathrm{mM}$ and amino donor concentration maintained at 5 equivalents for each reaction. $\mathrm{KCl}$ and DMF concentrations were $1 \mathrm{M}$ and $30 \%$ respectively, with each reaction carried out in triplicate. Reactions were quenched with $800 \mu \mathrm{L} 62.5 \%$ acetonitrile at regular time intervals and denatured protein was removed by centrifugation. The concentration of acetophenone coproduct formation was determined as described above. BC61-TAm concentration was determined using a combination of a Qubit ${ }^{\circledR} 2.0$ Fluorometer (Invitrogen, UK) and SDS-PAGE densitometry.

\section{Molecular modelling and substrate docking}

Molecular models of BC61-TAm were constructed using the I-TASSER server (https://zhanglab.ccmb.med.umich.edu/ITASSER) followed by energy minimisation using Yasara (Krieger et al. 2009). Molecular models of PMP and $\alpha-K G$ were constructed in Ascalaph Designer and subject to 1000 steps of steepest descent energy minimisation. The fidelity of the BC61-TAm model was assessed using the tools of the Whatif server along with Ramachandran analysis. Molecular models and docked complexes were viewed and manipulated in PyMol (DeLano 2002).

AutoDock Vina was utilised for the docking of both PMP and $\alpha-K G$ in two separate docking events (Trott and Olson 2010). Yasara energy minimisation was conducted following each docking step resulting in the production of the final docked complex. Construction of residue interaction maps was carried out using LigPlus followed by visualisation in PyMol.

\section{Molecular dynamics simulations}

Hydrogen atoms were added to simulated systems according to protonation states of individual residues with protonatable side chains at physiological $\mathrm{pH}$ following pKa analysis using PROPKA (Rostkowski et al. 2011). A molecule of DMF was constructed within Ascalaph Designer and subject to 1000 steps of steepest descent energy minimisation. Parameterisation of DMF was carried out using the PRODG server and a compatible GROMOS topology subsequently produced (Schüttelkopf and Van Aalten 2004).

All proteins were immersed within truncated octahedral boxes of explicit solvent (TIP3P water) with a minimum clearance of $20 \AA$ between periodic images for starting configurations. Solvent molecules were replaced with 2433 molecules of DMF to leave a final concentration of $30 \%$ in DMF simulations. The GROMOS96 54a7 force field was utilised for all simulations. Solvent molecules were replaced with $\mathrm{Na}^{+}$and $\mathrm{Cl}^{-}$ions to neutralise all charges and leave a final physiological concentration of $100 \mathrm{mM}$ by using the genion facility of Gromacs v4.6.5 (Hess et al. 2008).

Steepest descent energy minimisation was carried out on all simulations with an energy step of 0.01 , until a maximum potential force of $<1000 \mathrm{~kJ} \mathrm{Mol}^{-1}$ was achieved. The Verlet cutoff scheme was utilised with particle mesh Ewald (PME) treatment of electrostatic interactions (Grubmüller et al. 1991; Darden et al. 1993). Energy, pressure and temperature were monitored for the entirety of the simulation set up. NVT equilibration was carried out for 100 ps with a 2 -fs integration step. The LINCS algorithm with holonomic constraints was used to constrain all bonds (Hess et al. 1997). PME was implemented for long-range electrostatics with a $9 \AA$ cutoff for the real-space term and non-bonded Van der Waals interactions were calculated using LennardJones 12-6 potentials with a $9 \AA$ cutoff. Velocities were derived from a Maxwell distribution. A similar set up was used for a subsequent NPT equilibration with ParrinelloRahman pressure coupling implemented (Parrinello and Rahman 1980). Periodic boundary conditions were used for the systems with cutoff radii of $1 \mathrm{~nm}$. Systems then underwent simulation for a total time of $10 \mathrm{~ns}$ with 2 -fs integration time. Coordinates were saved every 10 ps. Triplicate simulations were conducted for both BC61TAm in water and in $30 \%$ DMF and were run on the high performance computing cluster at Queen's University Belfast.

Analysis of system properties was conducted using intrinsic tools of Gromacs v4.6.5 along with Chimera and PyMol for the manipulation of models and their subsequent visualisation. Graphs were subsequently produced within the $\mathrm{R}$ programming language. 
BC61-TAm gene and protein sequences

BC61-TAm sequence data was deposited using the BankIt sequence submission tool. Gene sequence data can be found in the GenBank database with Accession Number MK248484.1 and protein sequence data can be found in the GenPept database with Accession Number AZS32940.1.

\section{Results}

\section{Organism identification and gene selection}

The organism, from which the TAm enzyme was cloned and expressed, was isolated from a brine sample from Kilroot salt mine and given the designation CSM-61. Using the BLASTn function of the NCBI database, the organism was found to be a member of the genus Halorubrum, with the closest neighbour deemed to be Halorubrum saccharovorum JCM 8865.

On uploading the assembled contigs from Whole Genome Sequencing data to the RAST server (Aziz et al. 2008), the subsystems search tool revealed 19 results using the search term 'aminotransferase'. The gene chosen was $930 \mathrm{bp}$ in length and the corresponding protein was given the designation BC61-TAm.

\section{Expression and phylogenetic analysis}

SDS-PAGE analysis following IMAC purification showed a 34-35-kDa protein, commensurate with gene length and predicted size from the amino acid sequence (Fig. 1). Using a BLASTp search of the NCBI database, the closest neighbour to BC61-TAm was deemed to be a BCAT (fold type IV of the PLP superfamily), from Halorubrum sp. (Hp-TAm), at 94\% identity (NCBI Reference Sequence WP_099256159.1).

The phylogeny of BC61-TAm was investigated alongside a number of previously described TAms. Sequences were selected from both PLP fold types I and IV for comparison. PLP fold type I enzymes included $(S)$-selective $\omega$-TAms from mesophilic bacteria (Vf-TAm from Vibrio fluvialis (PDB: 3NUI_A), Cv-TAm from Chromobacterium violaceum (NCBI Reference Sequence: WP_011135573.1), Pp-TAm from Pseudomonas putida (UniProtKB/Swiss-Prot: P28269.1)) and halophilic bacteria (Hs-TAm from Halomonas sp. (GenBank: KUJ87738.1) and Ad2-TAm (Kelly et al. 2017)). PLP fold type IV enzymes included $(R)$-selective $\omega$-TAms (Arth-TAm from Arthrobacter sp. KNK168 (Genbank: BAK39753.1) and At-TAm from Aspergillus terreus (PDB: 4CE5 B)) and BCATs from both mesophilic bacteria (Ec-TAm from E. coli (PDB: 1IYE_A)) and haloarchaea (Hp-TAm) (Fig. 2).

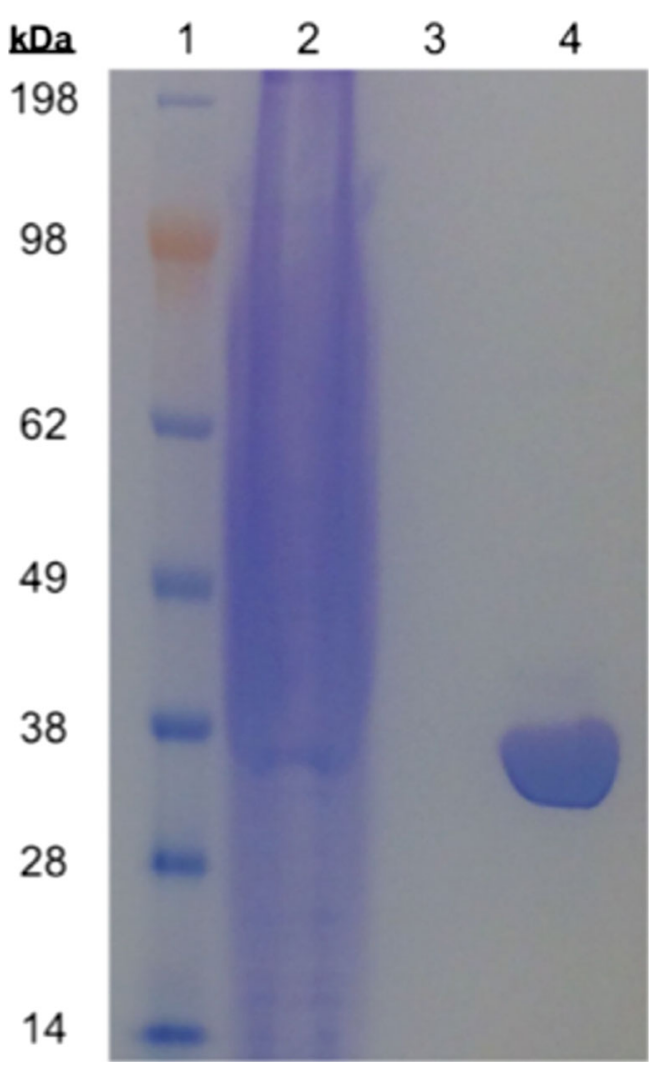

Fig. 1 SDS-PAGE of pre-purified clarified cell-free extract (lane 2) and BC61-TAm fraction, purified by IMAC (lane 4), alongside SeeBlue ${ }^{\circledR}$ Plus2 Protein standard (lane 1) and buffer used for protein elution (lane 3 )

BC61-TAm contained a higher proportion of the acidic amino acids, aspartate and glutamate $(19.42 \%)$, versus those from the mesophilic bacterial TAms, Cv-TAm, PpTAm, Vf-TAm, Ec-TAm, and Arth-TAm (12.21\%). The overall proportion of lysine residues was lower in BC61$\mathrm{TAm}$ at $1.94 \%$ than with the same mesophilic bacterial TAms at $3.96 \%$.

\section{Evaluation of enzyme performance under varying reaction parameters}

BC61-TAm was shown to be an $(R)$-selective TAm with its ability to utilise $(R)$-MBA as an amino donor, whilst not accepting the $(S)$-isomer. For both $\mathrm{NaCl}$ and $\mathrm{KCl}$, conversion of $\alpha-\mathrm{KG}$ improved with the addition of salt to the reaction versus no salt, with $100 \%$ relative conversion seen at $1 \mathrm{M}$ for both salts. Conversions remained high with increasing salinities beyond $1 \mathrm{M}$, with 95.4, 91.9 and $63.8 \%$ relative conversions observed for 2,3 and $4 \mathrm{M} \mathrm{NaCl}$ respectively, relative to the conversion seen at $1 \mathrm{M}$ (Fig. 3a).

BC61-TAm performed well in a number of scenarios with increasing levels of organic solvent (Fig. 3b). Greatest overall conversions were seen with $30 \%$ DMF 
Fig. 2 Multiple alignment of amino acid sequences of BC61-

TAm with a number of previously reported TAm sequences, including (S)-selective TAms from mesophilic bacteria $(\mathrm{Cv}$ TAm, Vf-TAm, and Pp-TAm) and halophilic bacteria (Hs-TAm and Ad2-TAm), (R)-selective $\omega$ -

TAms from bacteria and fungi (Arth-TAm and At-TAm respectively), and BCATs from bacteria (Ec-TAm) and haloarchaea (Hp-TAm and BC61TAm)

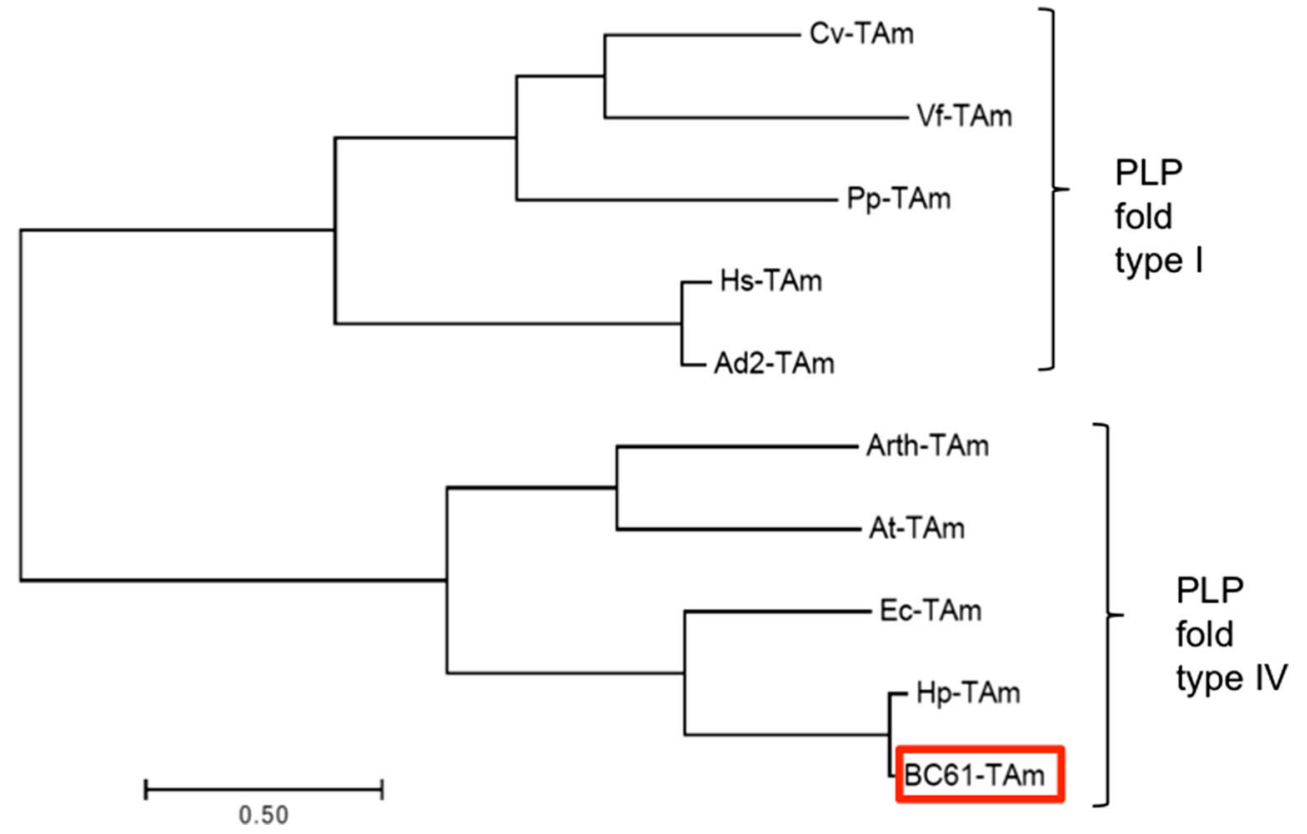

in the reaction mix, although BC61-TAm also performed well when the reaction was supplemented with DMSO.

Optimal conversion in the BC61-TAm-catalysed reaction was observed at $50{ }^{\circ} \mathrm{C}$ (Fig. 3c) and pH 8.0 (Fig. 3d).

Despite being annotated as a BCAT, BC61-TAm was able to produce $17.4 \%$ conversion of $\alpha-\mathrm{KG}$ using $(R)$ MBA as amino donor, with a specific activity of $73.22 \mathrm{U} / \mathrm{mg}$, where one unit is defined as the amount of enzyme producing $1 \mathrm{nmol}$ of acetophenone per minute. $\mathrm{Km}$ was determined as $3.37 \mathrm{mM}$ and kcat as $2.52 \mathrm{~min}^{-1}$.

\section{Modelling and molecular dynamics of BC61-TAm}

The primary template utilised for the threading process of the BC61-TAm model was the PDB entry 6NST. Ramachandran analysis of the finalised BC61-TAm model revealed that $95.1 \%$ of residues lie within favoured regions, with none in
Fig. 3 The effect of changing various parameters on the amination of $\alpha-\mathrm{KG}$ using purified BC61-TAm and (R)-MBA as amino donor, with acetophenone formation measured at $240 \mathrm{~nm}$. Plotted values are the mean of triplicate measurements, with error bars representing \pm standard deviation. In each graph, conversion is reported relative to the highest value observed for each parameter. (Abbreviations shown in panel B: DMSO, dimethyl sulfoxide; THF, tetrahydrofuran; DMF, dimethylformamide; $\mathrm{MeOH}$, methanol; iPrOH, isopropanol)
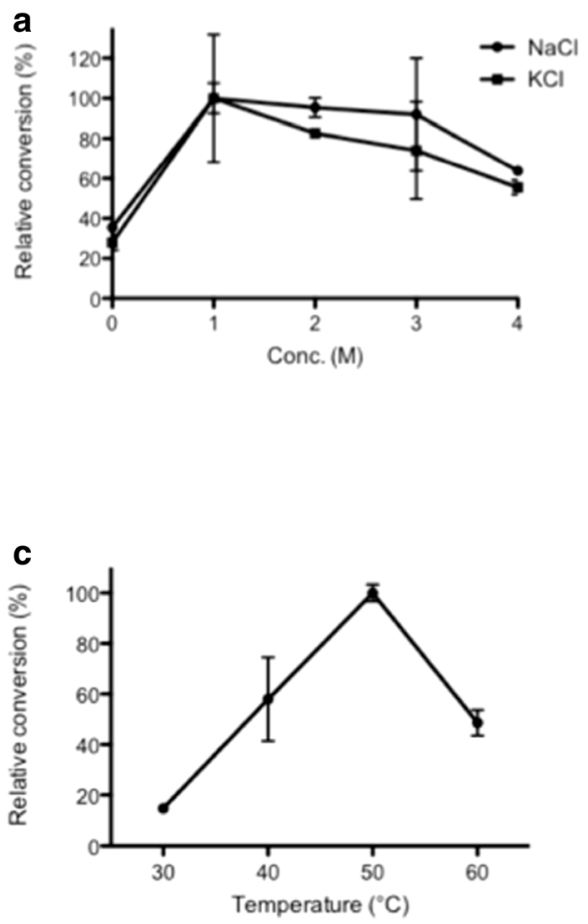
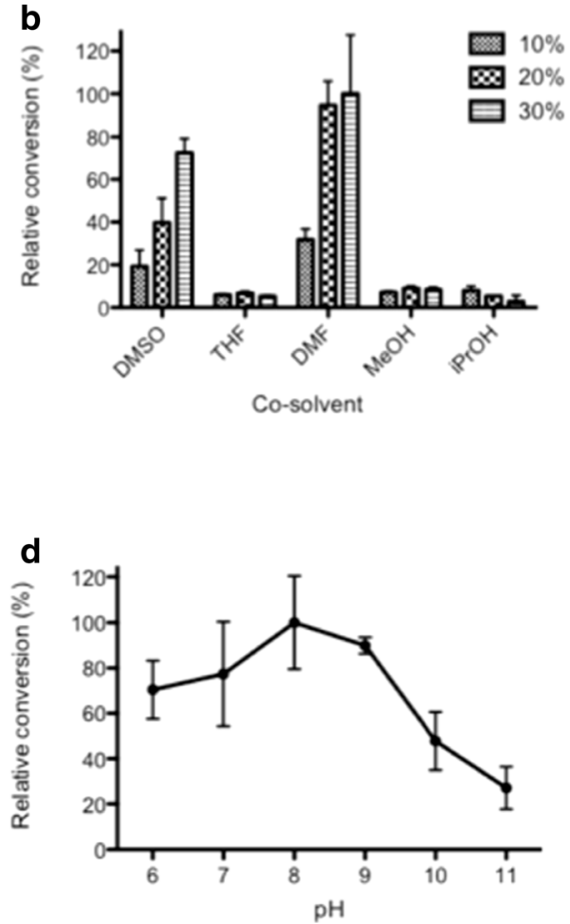

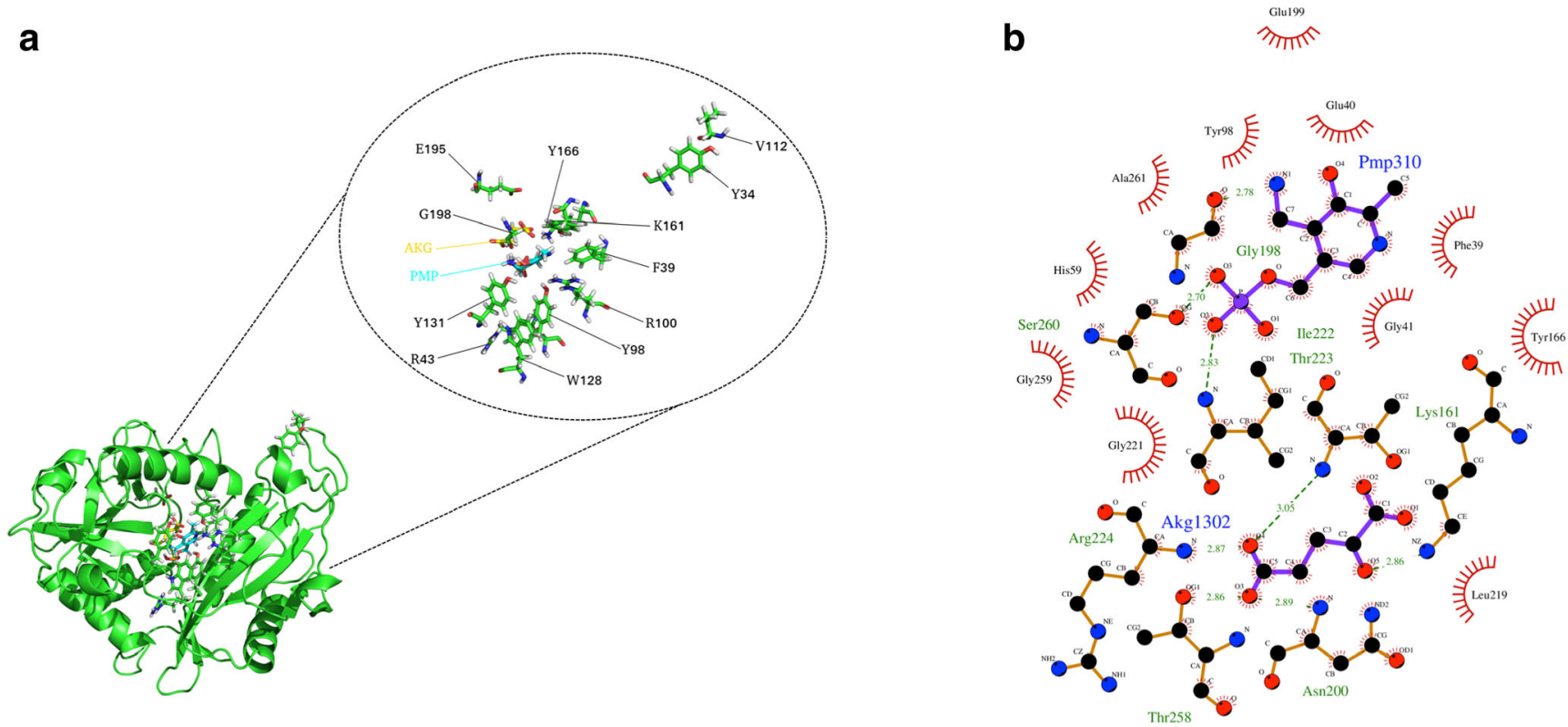

Fig. 4 a Molecular model of BC61-TAm constructed using I-TASSER server followed by energy minimization using Yasara, showing docked $\alpha-K G$ substrate $(\mathrm{AKG})$ and cofactor (PMP). Models and docked complexes were viewed and manipulated using PyMol. b 2D ligand

disallowed space. Iterative docking of PMP and $\alpha-\mathrm{KG}$ resulted in the production of a predicted final complex (Fig. 4a). LigPlus analysis of the bound complex revealed a number of residue interactions, including contributions by K161, which is a likely candidate for catalysis in the transamination reaction (Fig. 4b).

In an attempt to elucidate potential explanations for solvent enhanced activity, the BC61-TAm model was subject to molecular dynamics simulations in both water and 30\% DMF. Analysis of Replicate Root Mean Square Deviation (RMSD) simulations shows substantial similarity between the water and DMF systems, suggesting they follow similar movement trajectories (Online Resource, Fig. S1). Analysis of average Root Mean Square Fluctuation (RMSF) for the simulations reveals a similar flexibility profile is conserved across all residues in the water and DMF simulations, suggesting similar movement profiles. However, in the DMF simulations, there is increased flexibility compared with that of water alone (Fig. 5a).

The solvation shell surrounding BC61-TAm was simulated in both water and 30\% DMF systems, and water molecules were coloured according to a blue/white/red scheme corresponding to increasing density (Fig. $5 \mathrm{c}, \mathrm{d}$ ). In the water only simulation, a universal distribution of water molecules around the protein is observed. Disruption of the solvation shell in comparison with the water-only simulation is apparent, but by far the highest level of water density is observed in the active site cavity. The DMF also appears to contribute to this solvation shell (Online Resource - Fig. S2). The number of hydrogen bonds over time is also calculated for these simulations. map showing docking and interacting residues between $\alpha$-KG substrate (Akg1302), cofactor PMP (Pmp310) and BC61-TAm. Construction of residue interaction maps was carried out using LigPlus with subsequent visualisation in PyMol

When the lower number of water molecules in the DMF simulations is accounted for, the total number of bonds is not significantly different between the two (Fig. 5b). Additionally, analysis of the solvent accessible surface area (SASA) reveals that the DMF simulations possess a higher total SASA than the water-only simulations (Online Resource - Fig. S3).

\section{Discussion}

Of the 19 results obtained using the search term 'aminotransferase', those belonging to PLP fold types I and IV were selected for further study, as they are known to be industrially relevant (Steffen-Munsberg et al. 2015). The gene coding for BC61-TAm was annotated as a 'branched-chain amino acid aminotransferase' (BCAT). Following cloning and expression, this produced an active protein and was characterised further. As expected, phylogenetic analysis grouped BC61TAm with PLP fold type IV proteins, and was most closely related to the BCATs (Fig. 2). Residue analysis revealed a considerably higher proportion of the acidic amino acids, aspartate and glutamate, contained within BC61-TAm versus those from the mesophilic bacterial TAms. A greater number of acidic residues on the protein surface is characteristic of haloarchaeal enzymes, with the additional carboxyl group allowing a hydration shell to be stabilised in highly ionic surroundings, thereby maintaining the protein's solubility at high salinity (Madern et al. 1995; Madigan and Oren 1999; Hough and Danson 1999). Conversely, numbers of basic lysine 

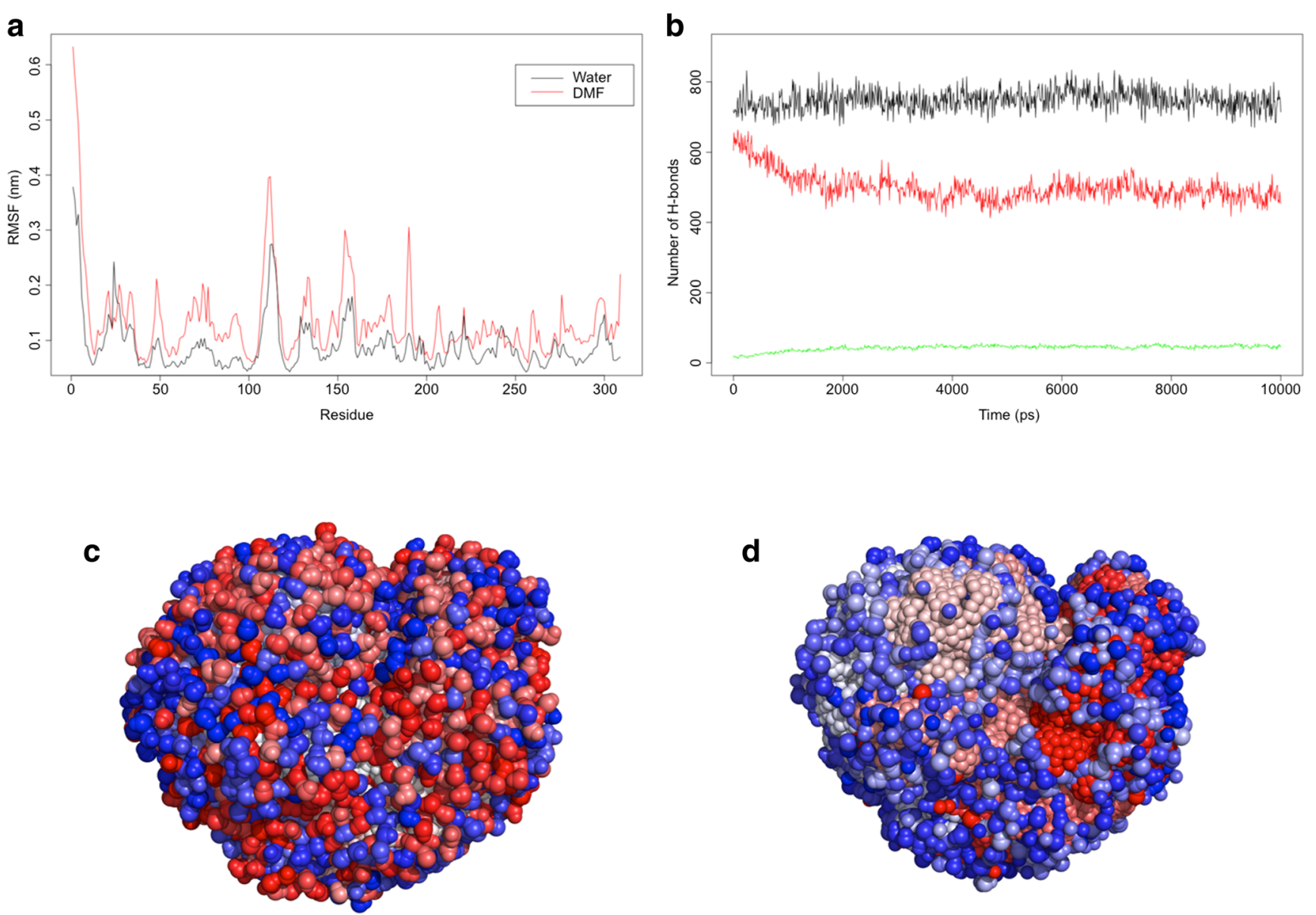

Fig. 5 a Simulation showing Root Mean Square Fluctuation across individual residues of BC61-TAm in both water and 30\% DMF. b Simulation predicting number of hydrogen bonds formed between water molecules and BC61-TAm protein in water (black line) and 30\% DMF (red line). Number of $\mathrm{H}$ bonds between DMF and BC61-TAm in

residues are decreased at the protein's surface (Danson and Hough 1997; DasSarma and DasSarma 2015). This was also proven to be the case with BC61-TAm when compared with mesophilic TAms.

Although annotated as a BCAT, which utilise branchedchain amino acids as amino donors, BC61-TAm also accepted MBA as amino donor. The ability of BCATs to accept amines as amino group donors has been reported previously in bacterial TAms (Kim et al. 2018), but such a phenomenon has not been described in the archaea. TAms possessing both BCAT and $\omega$-TAm activity can be attributed to the common ancestry shared among PLP fold type IV enzymes (Pavkov-Keller et al. 2016; Kim et al. 2018). Such a relationship is exemplified by the $(R)$-selective $\omega$-TAms, Arth-TAm and At-TAm, and the BCATs, Ec-TAm, Hp-TAm, and BC61-TAm, shown in Fig. 2.

BC61-TAm was shown to be an $(R)$-selective TAm with its ability to utilise $(R)$-MBA as an amino donor, whilst not accepting the $(S)$-isomer. This is a key characteristic of BC61-TAm, given the relative paucity of $(R)$-selective

enzymes in the current toolbox and the need for optical purity in many pharmaceuticals.

BC61-TAm displayed a typically halophilic profile when tested over a range of salinities, in that conversion improved with the addition of salt and high relative conversions were still observed up to $4 \mathrm{M} \mathrm{NaCl}$. The solvent tolerance exhibited represents a valuable feature of this enzyme and is characteristic of haloarchaeal enzymes as a whole. This trait also highlights the applicability of BC61-TAm, and similar enzymes, in processes requiring a high concentration of co-solvent, as often seen when substrate solubility is poor.

The usefulness of BC61-TAm is further exemplified by its preference for temperatures beyond the mesophilic range, with optimal conversion seen at $50{ }^{\circ} \mathrm{C}$. Halophilederived enzymes are known to be thermotolerant and, combined with tolerance to organic solvents, possess a profile which could prove extremely advantageous in a number of harsh reaction processes where mesophilic enzymes would fail to function. 
Unlike a number of enzymes from halophiles, which also possess an alkaliphilic profile, the optimal $\mathrm{pH}$ for BC61-TAm was pH 8.0 (Fig. 3d). This could be explained by BC61TAm's thalassohaline source, an environment formed from the evaporation of seawater, whereas alkaliphilic halophiles often derive from soda lakes and perform optimally at $\mathrm{pH} 9$ 10 (Hough and Danson 1999).

BC61-TAm was investigated for its ability to aminate a range of diverse aldehyde and ketone substrates, but of the compounds tested, it was only active against $\alpha-K G$. Despite this limited substrate scope, BC61-TAm shows desirable characteristics for industrial applications in its current form, particularly with respect to its tolerance to salt, organic solvent and increasing temperature, as well as being an $(R)$-selective TAm. In this regard, BC61-TAm represents a superb potential scaffold to which rational design can be applied in order to produce robust, novel biocatalysts.

Residues shown in the ligand map (Fig. 4b) reflect those of previously reported bacterial BCATs. Structural comparisons and searches revealed equivalent residues for all positions (Goto et al. 2003; De Chen et al. 2012), suggesting BC61TAm likely mediates catalysis according to a typical bacterial TAm pathway. This also suggests haloarchaeal TAms could provide effective scaffolds for rational design, as beneficial amino acid substitutions already known for bacterial TAms should confer the same advantages on TAms from haloarchaea. It is likely that the catalytic pathway of transamination has been conserved in BC61-TAm and has been coupled with the ability to not only tolerate solvents, but be enhanced by the presence of some organic solvents.

Molecular dynamics simulations revealed a number of insights into the improved performance of BC61-TAm in the presence of organic solvent. RMSF simulations showed increased flexibility across individual residues in the $30 \%$ DMF simulation compared to water alone. Organic solvents often confer a rigidifying effect on mesophilic proteins, but the increased flexibility observed with BC61-TAm may partially account for the improvement in conversion observed in the presence of DMF.

The hydration shell of a protein is critical to its function, with solvent-mediated disruption of this shell somewhat accounting for the typical rigidity and loss of function associated with most proteins. It seems that in the DMF simulations, BC61-TAm is able to retain a high density of water molecules within the active site cavity, a likely factor in the preservation of its activity despite the presence of solvent. This, along with DMF-mediated interactions, appears to provide a modified water solvent shell that imparts greater flexibility on BC61-TAm. Furthermore, the higher total SASA in the DMF simulation appears to be due to an increased hydrophobic contribution, likely attributable to the DMF. Along with the likely increase in substrate solubility provided by DMF, this provides a feasible mechanistic explanation as to the higher experimental activity observed.

To our knowledge, BC61-TAm is the first haloarchaeal TAm to be studied and characterised for biocatalytic application. BC61-TAm is $(R)$-selective and displays a number of adaptations which could prove useful in industrial processes, including thermotolerance, halophilicity and tolerance to organic solvents. Molecular dynamics simulations have predicted a number of mechanisms by which BC61-TAm exhibits solvent tolerance, a characteristic of particular interest in pharmaceutical biocatalysis. We therefore propose that BC61-TAm can serve as a useful first example of an organic solvent-tolerant, halophilic $(R)$-selective archaeal TAm, whose characteristics can help provide a scaffold for future biocatalyst mining and protein engineering.

Funding information This work was supported by the Biotechnology and Biological Sciences Research Council (BBSRC) through an Industrial CASE Training Grant BB/L017083/1 in partnership with Almac Sciences.

\section{Compliance with ethical standards}

Conflict of interest The authors declare that they have no conflict of interest.

Ethical approval This article does not contain any studies with human participants or animals performed by any of the authors.

Open Access This article is distributed under the terms of the Creative Commons Attribution 4.0 International License (http:// creativecommons.org/licenses/by/4.0/), which permits unrestricted use, distribution, and reproduction in any medium, provided you give appropriate credit to the original author(s) and the source, provide a link to the Creative Commons license, and indicate if changes were made.

\section{References}

Allers T, Ngo HP, Mevarech M, Lloyd RG (2004) Development of additional selectable markers for the halophilic archaeon Haloferax volcanii based on the leuB and trpA genes. Appl Environ Microbiol 70:943-953. https://doi.org/10.1128/AEM.70.2.943953.2004

Amoozegar MA, Siroosi M, Atashgahi S, Smidt H, Ventosa A (2017) Systematics of haloarchaea and biotechnological potential of their hydrolytic enzymes. Microbiology (United Kingdom) 163:623645. https://doi.org/10.1099/mic.0.000463

Aziz RK, Bartels D, Best AA, DeJongh M, Disz T, Edwards RA, Formsma K, Gerdes S, Glass EM, Kubal M, Meyer F, Olsen GJ, Olson R, Osterman AL, Overbeek RA, McNeil LK, Paarmann D, Paczian T, Parrello B, Pusch GD, Reich C, Stevens R, Vassieva O, Vonstein V, Wilke A, Zagnitko O (2008) The RAST Server: rapid annotations using subsystems technology. BMC Genomics 9:75. https://doi.org/10.1186/1471-2164-9-75

Baud D, Jeffries JWE, Moody TS, Ward JM, Hailes HC (2017) A metagenomics approach for new biocatalyst discovery: application to transaminases and the synthesis of allylic amines. Green Chem 19:1134-1143. https://doi.org/10.1039/c6gc02769e 
Bezsudnova EY, Boyko KM, Popov VO (2017) Properties of bacterial and archaeal branched chain amino acid aminotransferases. Biochem 82:1572-1591

Busto E, Gotor-Fernández V, Gotor V (2011) Hydrolases in the stereoselective synthesis of $\mathrm{N}$-heterocyclic amines and amino acid derivatives. Chem Rev 111:3998-4035. https://doi.org/10.1021/ cr100287w

Danson MJ, Hough DW (1997) The structural basis of protein halophilicity. Comp Biochem Physiol - A Physiol 117:307-312. https://doi.org/10.1016/S0300-9629(96)00268-X

Darden T, York D, Pedersen L (1993) Particle mesh Ewald: an N. $\log (\mathrm{N})$ method for Ewald sums in large systems. J Chem Phys 98:1008910092. https://doi.org/10.1063/1.464397

DasSarma S, DasSarma P (2015) Halophiles and their enzymes: negativity put to good use. Curr Opin Microbiol 25:120-126. https://doi. org/10.1016/j.mib.2015.05.009

Davies MT (1959) A universal buffer solution for use in ultra-violet spectrometry. Analyst 84:248-251. https://doi.org/10.1039/ AN9598400248

De Chen C, Lin CH, Chuankhayan P, Huang YC, Hsieh YC, Huang TF, Guan HH, Liu MY, Chang WC, Chena CJ (2012) Crystal structures of complexes of the branched-chain aminotransferase from Deinococcus radiodurans with $\alpha$-Ketoisocaproate and Lglutamate suggest the radiation resistance of this enzyme for catalysis. J Bacteriol 194:6206-6216. https://doi.org/10.1128/JB.0165912

DeLano W (2002) The PyMOL Molecular Graphics System (2002) DeLano Scientific, Palo Alto, CA, USA. http:/www.pymol.org

Doukyu N, Ogino H (2010) Organic solvent-tolerant enzymes. Biochem Eng J 48:270-282. https://doi.org/10.1016/j.bej.2009.09.009

Dourado DFAR, Pohle S, Carvalho ATP, Dheeman DS, Caswell JM, Skvortsov T, Miskelly I, Brown RT, Quinn DJ, Allen CCR, Kulakov L, Huang M, Moody TS (2016) Rational design of a (S)selective-transaminase for asymmetric synthesis of (1S)-1-(1,1'-biphenyl 2-yl)ethanamine. ACS Catal 6:7749-7759. https://doi.org/ 10.1021/acscatal.6b02380

Fuchs M, Koszelewski D, Tauber K, Kroutil W, Faber K (2010) Chemoenzymatic asymmetric total synthesis of (S)-rivastigmine using omega-transaminases. Chem Commun (Camb) 46:5500 5502. https://doi.org/10.1039/c0cc00585a

Ghislieri D, Turner NJ (2013) Biocatalytic approaches to the synthesis of enantiomerically pure chiral amines. Top Catal 57:284-300. https:// doi.org/10.1007/s11244-013-0184-1

Goto M, Miyahara I, Hayashi H, Kagamiyama H, Hirotsu K (2003) Crystal structures of branched-chain amino acid aminotransferase complexed with glutamate and glutarate: true reaction intermediate and double substrate recognition of the enzyme. Biochemistry 42 : 3725-3733

Grubmüller H, Heller H, Windemuth A, Schulten K (1991) Generalized Verlet algorithm for efficient molecular dynamics simulations with long-range interactions. Mol Simul 6:121-142

Guo F, Berglund P (2017) Transaminase biocatalysis: optimization and application. Green Chem 19:333-360. https://doi.org/10.1039/ C6GC02328B

Hess B, Bekker H, Berendsen HJC, Fraaije JGEM (1997) LINCS: a linear constraint solver for molecular simulations. J Comput Chem 18: 1463-1472. https://doi.org/10.1002/(SICI)1096-987X(199709)18: $12<1463::$ AID-JCC4>3.0.CO;2-H

Hess B, Kutzner C, Van Der Spoel D, Lindahl E (2008) GROMACS 4: algorithms for highly efficient, load-balanced, and scalable molecular simulation. J Chem Theory Comput 4:435-447. https://doi.org/ $10.1021 /$ ct700301q

Hough DW, Danson MJ (1999) Extremozymes. Curr Opin Chem Biol 3: 39-46. https://doi.org/10.1016/S1367-5931(99)80008-8

Humble MS, Cassimjee KE, Abedi V, Federsel HJ, Berglund P (2012) Key amino acid residues for reversed or improved enantiospecificity of an $\omega$-transaminase. ChemCatChem 4:1167-1172. https://doi.org/ $10.1002 /$ cctc. 201100487

Kelly SA, Megaw J, Caswell J, Scott CJ, Allen CCR, Moody TS, Gilmore BF (2017) Isolation and characterisation of a halotolerant $\omega$-transaminase from a Triassic period salt mine and its application to biocatalysis. ChemistrySelect 2:9783-9791. https://doi.org/10. 1002/slct.201701642

Kelly SA, Pohle S, Wharry S, Mix S, Allen CCR, Moody TS, Gilmore BF (2018) Application of $\omega$-transaminases in the pharmaceutical industry. Chem Rev 118:349-367. https://doi.org/10.1021/acs. chemrev.7b00437

Kim EM, Park JH, Kim BG, Seo JH (2018) Identification of (R)-selective $\omega$-aminotransferases by exploring evolutionary sequence space. Enzym Microb Technol 110:46-52. https://doi.org/10.1016/j. enzmictec.2017.12.002

Kohls H, Steffen-Munsberg F, Höhne M (2014) Recent achievements in developing the biocatalytic toolbox for chiral amine synthesis. Curr Opin Chem Biol 19:180-192. https://doi.org/10.1016/j.cbpa.2014. 02.021

Krieger E, Joo K, Lee J, Lee J, Raman S, Thompson J, Tyka M, Baker D, Karplus K (2009) Improving physical realism, stereochemistry, and side-chain accuracy in homology modeling: four approaches that performed well in CASP8. Proteins Struct Funct Bioinf 77:114 122. https://doi.org/10.1002/prot.22570.Improving

Kroutil W, Fischereder E-M, Fuchs CS, Lechner H, Mutti FG, Pressnitz D, Rajagopalan A, Sattler JH, Simon RC, Siirola E (2013) Asymmetric preparation of prim-, sec-, and tert-amines employing selected biocatalysts. Org Process Res Dev 17:751-759

Liliensiek AK, Cassidy J, Gucciardo G, Whitely C, Paradisi F (2013) Heterologous overexpression, purification and characterisation of an alcohol dehydrogenase (ADH2) from Halobacterium sp. NRC1. Mol Biotechnol 55:143-149. https://doi.org/10.1007/s12033013-9666-4

Littlechild JA (2015) Enzymes from extreme environments and their industrial applications. Front Bioeng Biotechnol 3:1-9. https://doi. org/10.3389/fbioe.2015.00161

Madern D, Pfister C, Zaccai G (1995) Mutation at a single acidic aminoacid enhances the halophilic behaviour of malate dehydrogenase from Haloarcula marismortui in physiological salts. Eur J Biochem 230:1088-1095

Madigan MT, Oren A (1999) Thermophilic and halophilic extremophiles. Curr Opin Microbiol 2:265-269. https://doi.org/10.1016/S13695274(99)80046-0

Malik MS, Park E-S, Shin J-S (2012) Features and technical applications of omega-transaminases. Appl Microbiol Biotechnol 94:1163-1171

Mangion IK, Sherry BD, Yin J, Fleitz FJ (2012) Enantioselective synthesis of a dual orexin receptor antagonist. Org Lett 14:3458-3461. https://doi.org/10.1021/ol3014123

Midelfort KS, Kumar R, Han S, Karmilowicz MJ, McConnell K, Gehlhaar DK, Mistry A, Chang JS, Anderson M, Villalobos A, Minshull J, Govindarajan S, Wong JW (2013) Redesigning and characterizing the substrate specificity and activity of Vibrio fluvialis aminotransferase for the synthesis of imagabalin. Protein Eng Des Sel 26:25-33. https://doi.org/10.1093/protein/gzs065

Muriana FJ, Alvarez-Ossorio MC, Relimpiot AM (1991) Purification and characterization of aspartate aminotransferase from the halophile archaebacterium Haloferax mediterranei. Biochem J 278:149-154

Nobili A, Steffen-Munsberg F, Kohls H, Trentin I, Schulzke C, Höhne M, Bornscheuer UT (2015) Engineering the active site of the amine transaminase from Vibrio fluvialis for the asymmetric synthesis of aryl-alkyl amines and amino alcohols. ChemCatChem 7:757-760. https://doi.org/10.1002/cctc.201403010

Nuttall S, Bath C, Pfeiffer M, Santos F, Eichler J, Mcalpine T (2009) The Halohandbook. 1-144

Parrinello M, Rahman A (1980) Crystal structure and pair potentials: a molecular-dynamics study. Phys Rev Lett 45:1196-1199 
Pavkov-Keller T, Strohmeier GA, Diepold M, Peeters W, Smeets N, Schürmann M, Gruber K, Schwab H, Steiner K (2016) Discovery and structural characterisation of new fold type IV-transaminases exemplify the diversity of this enzyme fold. Sci Rep 6:38183. https://doi.org/10.1038/srep38183

Rostkowski M, Olsson MH, Søndergaard CR, Jensen JH (2011) Graphical analysis of $\mathrm{pH}$-dependent properties of proteins predicted using PROPKA. BMC Struct Biol 11:6-11. https://doi.org/10.1186/ 1472-6807-11-6

Savile CK, Janey JM, Mundorff EC, Moore JC, Tam S, Jarvis WR, Colbeck JC, Krebber A, Fleitz FJ, Brands J, Devine PN, Huisman GW, Hughes GJ (2010) Biocatalytic asymmetric synthesis of chiral amines from ketones applied to sitagliptin manufacture. Science 329:305-309. https://doi.org/10.1126/science.1188934

Schätzle S, Höhne M, Redestad E, Robins K, Bornscheuer UT (2009) Rapid and sensitive kinetic assay for characterization of $\omega$-transaminases. Anal Chem 81:8244-8248. https://doi.org/10.1021/ ac901640q

Schüttelkopf AW, Van Aalten DMF (2004) PRODRG: a tool for highthroughput crystallography of protein-ligand complexes. Acta Crystallogr Sect D Biol Crystallogr 60:1355-1363. https://doi.org/ 10.1107/S0907444904011679

Sharma M, Mangas-Sanchez J, Turner NJ, Grogan G (2017) NAD(P)Hdependent dehydrogenases for the asymmetric reductive amination of ketones: structure, mechanism, evolution and application. Adv Synth Catal 359:2011-2025. https://doi.org/10.1002/adsc. 201700356
Steffen-Munsberg F, Vickers C, Kohls H, Land H, Mallin H, Nobili A, Skalden L, van den Bergh T, Joosten H-J, Berglund P, Höhne M, Bornscheuer UT (2015) Bioinformatic analysis of a PLP-dependent enzyme superfamily suitable for biocatalytic applications. Biotechnol Adv 33:566-604. https://doi.org/10.1016/j.biotechadv. 2014.12.012

Stroud A, Liddell S, Allers T (2012) Genetic and biochemical identification of a novel single-stranded DNA-binding complex in Haloferax volcanii. Front Microbiol 3:1-14. https://doi.org/10.3389/fmicb. 2012.00224

Svedendahl M, Branneby C, Lindberg L, Berglund P (2010) Reversed Enantiopreference of an $\omega$-transaminase by a single-point mutation. ChemCatChem 2:976-980. https://doi.org/10.1002/cctc.201000107

Trott O, Olson A (2010) AutoDock Vina: improving the speed and accuracy of docking with a new scoring function, efficient optimization, and multithreading. J Comput Chem 31:455-461. https://doi.org/10. 1002/jcc.21334.AutoDock

Woese CR, Kandler O, Wheelis ML (1990) Towards a natural system of organisms: proposal for the domains Archaea, Bacteria, and Eucarya. Proc Natl Acad Sci 87:4576-4579. https://doi.org/10. 1073/pnas.87.12.4576

Publisher's note Springer Nature remains neutral with regard to jurisdictional claims in published maps and institutional affiliations. 